\title{
Integração entre o sistema de gestão acadêmica e o sistema de gestão da aprendizagem: identificando necessidades e prototipando requisitos favoráveis à prática docente
}

\author{
Rosângela Saraiva Carvalho, ${ }^{1,2}$ \\ Ivanildo José de Melo Filho, ${ }^{1,3}$ \\ Tiago Carvalho Vidal ${ }^{1}$ \\ Rosangela Maria de $\mathrm{Melo}^{3,4}$ \\ Alex Sandro Gomes ${ }^{1}$
}

\begin{abstract}
Resumo: O presente trabalho tem como objetivo identificar a forma adequada da integração entre os sistemas de gestão acadêmica e de gestão da aprendizagem favoráveis à prática docente. Para tanto, foram realizadas entrevistas, análises documentais, e aplicações de questionários com docentes que atuam nas diversas modalidades de ensino. Os resultados obtidos permitiram descrever a integração entre esses dois tipos de sistemas de modo a promover motivações e atender às necessidades identificadas visando simplificar, otimizar e auxiliar o docente em sua prática. Os resultados foram prototipados e reportados à comunidade do LMS Amadeus no PSPB - Portal do Software Público Brasileiro do Ministério do Planejamento do Brasil.
\end{abstract}

Palavras-chave: Sistema de gestão acadêmica. Sistema de gestão da aprendizagem. Prática docente.

\begin{abstract}
This paper is intended to identify the proper way of integration between the academic management and learning management systems of learning conducive to teaching practice. In order to support this objective, interviews, document analysis and questionnaires with high education teachers who work in different teaching areas were performed. The results led to describe the integration between these two types of systems to promote motivation and meet the needs identified in order to simplify, optimize, and assist teachers in their practice. The results were prototyped and reported to the LMS community in PSPB Amadeus - Brazilian Public Software Portal of the Ministry of Planning of the Federative Republic of Brazil.
\end{abstract}

Keywords: Academic management system. Learning management system. Practical professor activities.

\section{Introdução}

Segundo Fonseca [1], é de grande importância o papel da educação no desenvolvimento humano. Nesse sentido, o papel do docente é fundamental, sendo necessário que este reflita, constantemente, sobre sua prática. Conforme evidencia Perrenoud [2], "A autonomia e a responsabilidade de um profissional dependem de uma grande capacidade de refletir em e sobre sua ação".

A reflexão do docente sobre sua prática é de suma importância, visto que o resultado do trabalho docente depende diretamente da autoavaliação, acerca de suas ações, decisões e escolhas, afirma Tardiff [3].

\footnotetext{
${ }^{1}$ Centro de Informática - Universidade Federal de Pernambuco, Pernambuco - Brasil - Av. Jornalista Aníbal Fernandes, s/n Cidade Universitária - 50.740-560 - Recife: PE.

\{rosangelac@gmail.com, ivanildo.melo@belojardim.ifpe.edu.br, tiagocv@gmail.com, asg@cin.ufpe.br\}

${ }^{2}$ Escola Superior de Relações Públicas - PE

${ }^{3}$ Instituto Federal de Pernambuco - Campus Belo Jardim, Pernambuco - Brasil.

${ }^{4}$ Instituto de Tecnologia de Pernambuco.

\{rmdemelo@gmail.com\}
}

http://dx.doi.org/10.5335/rbca.2012.1951 
Atualmente, o governo e a sociedade civil procuram alternativas para melhorar a educação nacional em todos os seus níveis. Nesse cenário, as tecnologias da informação e comunicação (TIC) têm auxiliado o docente em sua tarefa de ensinar. Assim, conforme Santos, Luis e Silva [4] a busca dos profissionais de educação em superar as dificuldades no que concerne à sua prática, especialmente no que diz respeito à sala de aula, inclui a inserção da tecnologia às práticas educacionais.

Desse modo, a pesquisa descrita neste trabalho centrou-se nos aspectos favoráveis à prática docente que podem advir da integração entre um sistema de gestão acadêmica e um sistema de gestão da aprendizagem. Por conseguinte, foram identificadas as necessidades oriundas dessa integração, a partir dessas foram estabelecidos requisitos e sugeridos protótipos para o LMS Amadeus 5 .

O presente trabalho está organizado da seguinte forma: a seção 2 aborda conceitos sobre os sistemas de gestão acadêmica e da aprendizagem, a seção 3 trata da metodologia adotada nesta pesquisa; a seção 4 expõe os resultados encontrados; a seção 5 apresenta os requisitos estabelecidos e alguns protótipos sugeridos e, por fim, a seção 6 evidencia as considerações finais.

\section{Sistema de gestão acadêmica e sistema de gestão da aprendizagem}

Os sistemas de gestão acadêmica são sistemas de informação que, comumente, disponibilizam funcionalidades de controle quanto a dados cadastrais de discentes, docentes, cursos, perfis curriculares: disciplinas, requisitos, equivalências, associações; oferta de turmas a cada período letivo; pré-matrícula e matrícula de discentes; lançamento de notas on-line pelos docentes; histórico escolar; dados do Enade ${ }^{6}$; registro de diplomas, entre outras funcionalidades que auxiliam o controle administrativo das instituições de ensino.

Numa instituição de ensino, um sistema deste tipo é uma ferramenta fundamental para o controle dos processos administrativos e da gestão acadêmica. No geral, os sistemas de gestão acadêmica propõem-se a controlar e a agilizar os processos da instituição, possibilitando a consolidação de informações importantes para a gestão, através da análise de dados, tais como matrículas, aproveitamento acadêmico, frequência, evasão, entre outros indicadores.

Por outro lado, o Sistema de Gestão da Aprendizagem, ou LMS - Learning Management System -, compreende funcionalidades definidas para armazenar, distribuir e gerenciar conteúdos de aprendizado de forma interativa e gradativa. O principal objetivo dos ambientes LMS consiste em dar suporte ao processo de e-Learning, ${ }^{7}$ possibilitando o ensino e aprendizagem em diversas modalidades: a distância, de forma semipresencial, ou de forma mesclada, que também é denominada Blended Learning ou b-Learning. Tais ambientes viabilizam e facilitam distintas formas de interação dos discentes com o conteúdo, com o docente e entre si.

O LMS ou AVA ${ }^{8}$ é composto por um conjunto de sistemas: “[...] a definição de Minshull (2004), segundo a qual a AVA é um software que reúne diferentes ferramentas e funções, notadamente: (i) gerenciamento e transmissão de conteúdo; (ii) comunicação; (iii) avaliação, (iv) registro e andamento das atividades e (v) funcionalidades administrativas. O diferencial dos AVA em relação a material para auto-estudo disponibilizado na Web é, justamente, o foco nas interações estudante-estudante estudante-instrutor." [5]

Nesses ambientes a informática é ferramenta imprescindível ao processo de ensino-aprendizagem. O LMS é um tipo de software que busca proporcionar a construção do conhecimento individual dos discentes através da discussão, reflexão e colaboração. Esses sistemas transformaram as relações de tempo e espaço e a relação entre

\footnotetext{
${ }^{5}$ O LMS Amadeus ou Ambiente Virtual de Aprendizagem Amadeus tem origem em um conjunto de pesquisas acadêmicas nas áreas de interação humano computador e tecnologia educacional. Foi desenvolvido pelo grupo de pesquisa Ciências Cognitivas e Tecnologia Educacional (CCTE) do Centro de Informática da Universidade Federal de Pernambuco. Esse LMS é definido como um sistema de gestão de aprendizagem para educação presencial, a distância e todas as suas variações. É baseado no conceito de blended learning, segundo o qual, para se atingir um grande público com projetos de formação a distância, faz-se necessário uma combinação de formas de mediar a apresentação e as interações com os conteúdos das aulas. A interação entre os usuários, e destes com o conteúdo no ambiente, permite a execução de novas estratégias de ensino e de aprendizagem orientadas por teorias construtivistas ou sociointeracionista do desenvolvimento humano. O LMS Amadeus é distribuído sob uma licença de software livre, e desde março de 2009 passou a integrar o PSPB5 - Portal do Software Público Brasileiro. Atualmente, a comunidade do LMS Amadeus no PSPB conta com, aproximadamente, 4.500 participantes. Maiores informações podem ser obtidas através do PSPB na internet disponível em: $<$ http://www.softwarepublico.gov.br $>$.

${ }^{6}$ Exame Nacional de Desempenho de Estudantes, disponível em: $<$ http://www.inep.gov.br/superior/enade/enade_default.htm>.

${ }^{7}$ Tecnicamente, o e-learning é o ensino realizado através de meios eletrônicos, (Felipini, 2009).

${ }^{8}$ AVA - Ambiente Virtual de Aprendizagem.
} 
discente e docente que, nesse contexto, pode extrapolar a sala de aula. O LMS, dessa forma, pode estar presente em todas as fases da prática docente da modalidade de ensino a distância ou semipresencial com o propósito de facilitar e viabilizar a docência.

\section{Método}

A pesquisa foi realizada a partir de uma abordagem qualitativa e teve como objetivo investigar os aspectos favoráveis advindos da integração entre o sistema de gestão acadêmica e o sistema de gestão da aprendizagem na prática docente. Escolheu-se tal abordagem tendo em vista que a pesquisa foi definida utilizando-se, como princípios, a reflexão sobre a prática docente e o uso da tecnologia voltado para a educação, não como um fim, mas como um meio.

\subsection{Contexto}

O contexto desta pesquisa é a prática docente com os sistemas de gestão acadêmica e da aprendizagem nas modalidades de ensino presencial, semipresencial ou a distância. Na seleção das instituições pesquisadas foram considerados três critérios: o primeiro visou às instituições, nas quais os docentes utilizam em sua prática pedagógica apenas sistema de gestão acadêmica, restringindo-se estes ao " $A$ " ou "B"; o segundo critério consistiu em uma busca por instituições que utilizam apenas sistema de gestão da aprendizagem, no caso o LMS Amadeus ou Moodle; ${ }^{9}$ como terceiro critério foram consideradas as instituições que adotam os dois tipos de sistemas citados: de gestão acadêmica e de gestão da aprendizagem.

\subsection{Participantes}

Os docentes entrevistados foram selecionados aleatoriamente. As instituições pesquisadas foram: UFRN Universidade Federal do Rio Grande do Norte, SENAI - Unidade Natal e ESURP - Escola Superior de Relações Públicas que atuam nas modalidades de ensino presencial, ensino a distância ou em ambas.

É importante ressaltar que tanto os sistemas de gestão acadêmica como os de gestão da aprendizagem selecionados estão integrados, ou em processo de integração, à prática pedagógica da atividade docente. Esse foi um dos principais motivos para a escolha destes sistemas.

\subsection{Técnicas}

As técnicas utilizadas visaram descrever o comportamento da prática docente nos dois ambientes: sistema de gestão acadêmica e sistema de gestão da aprendizagem. Assim, para identificar os aspectos favoráveis à prática docente, provenientes da integração entre esses dois sistemas, foram realizadas entrevistas semiestruturadas, seguidas de uma análise documental e da aplicação de questionários. Esses instrumentos foram utilizados considerando-se que:

- a técnica da entrevista propicia uma relação de interação, podendo resultar na influência recíproca entre quem pergunta e quem responde. Por intermédio da entrevista, o pesquisador pode obter imediatamente qualquer informação de posse do entrevistado, que considere necessária, desde que faça uso das técnicas adequadas; [6]

- a análise documental, segundo Lüdke e André, [6] “[...] complementa os dados obtidos através da observação e da entrevista e que aponta novos aspectos da realidade pesquisada";

- a aplicação de questionário, de acordo com Lopes, [7] "“...] constituem uma técnica bem estabelecida de coleta de dados demográficos e de opiniões de usuários. São semelhantes a entrevistas e podem conter perguntas abertas ou fechadas".

\subsection{Análise dos dados}

Os resultados foram estabelecidos a partir da observação da prática docente, após a análise de entrevistas e de documentos utilizados pelos docentes, com a qual foi possível obter detalhes de como tal atividade ocorre utilizando-se os sistemas de gestão acadêmica e de gestão da aprendizagem. A observação dessa prática foi feita sob

\footnotetext{
${ }^{9}$ Moodle (Modular Object-Oriented Dynamic Learning Environment) na internet. Disponível em: $<\mathrm{http}: / /$ moodle.org>.
} 
a ótica da integração desses dois tipos de sistemas e não se ateve a algum método ou técnica relacionados com o ensino e aprendizagem.

Dessa forma, realizaram-se entrevistas organizadas de forma semiestruturadas, nas quais se buscou criar condições para que houvesse um fluxo natural das informações advindas dos entrevistados. Para tal, considerou-se que os docentes normalmente desempenham muitos papéis na sua prática - planejamento didático, preparação de material de aprendizagem e ministração de aulas, em muitos casos, a partir de suas próprias concepções sobre o ensino e aprendizagem. Nesse sentido, de acordo com Lopes [8], os professores são produtores ao elaborarem as propostas de cursos; conselheiros ao acompanharem os alunos; parceiros, ao construírem, junto com os especialistas em tecnologia, abordagens inovadoras de aprendizagens. Novos tempos, novas tecnologias e nova cultura com a presença de educadores.

Portanto, com tantos papéis a exercer, fica clara a necessidade de o docente refletir constantemente sobre sua prática, de modo a atingir o objetivo mais importante do processo de ensino: a aprendizagem.

Assim, este trabalho é resultante do esforço para aproximar duas áreas - ensino e tecnologia - que, atualmente, complementam-se visando ao sucesso do processo de ensino-aprendizagem.

\section{$4 \quad$ Resultados}

Com base nas técnicas utilizadas nesta pesquisa e em relação aos objetivos definidos, os resultados alcançados demonstraram ser a discussão sobre a influência da integração dos dois sistemas muito mais ampla que o previsto inicialmente. Em razão disso, e por limitação de espaço, neste trabalho são apresentados apenas alguns dos aspectos favoráveis que justificam a importância da integração entre os sistemas supracitados e algumas das necessidades de funcionalidades a serem implementadas para que esta integração tenha êxito, bem como alguns requisitos e seus respectivos protótipos.

Com a entrevista, observou-se um índice de $75 \%$ de docentes que não sentem dificuldades em trabalhar com esses sistemas, pelo fato de eles possuírem designs diferentes, pois justificaram que a utilização dos dois é bem definida. No entanto, todos concordam que se os dois sistemas tivessem o mesmo design facilitaria em muito o desenvolvimento das atividades do dia a dia, para todos os usuários, quer sejam docentes, coordenadores, quer sejam discentes.

Convém ressaltar que tais sistemas possuem funcionalidades que se complementam, mas, por outro lado, há aquelas comuns que estão presentes nos dois ambientes. Fica a questão sobre qual ambiente deve-se usar as funcionalidades que se repetem? Qual ambiente o discente deverá acessar para encontrar a informação correta? Que garantias tem o discente de que está acessando a informação correta? Esses são questionamentos e dificuldades relatadas pelos docentes entrevistados, referentes à utilização de dois sistemas que não se encontrem integrados.

Outro ponto ressaltado pelos docentes que atuam nos dois sistemas diz respeito à necessidade frequente de executar a mesma atividade em ambos. Essa é uma prática considerada negativa pelos docentes, pois a repetição de atividades nos dois ambientes, além da perda considerável do tempo, pode resultar em inconsistência nos dados. Salienta-se ainda a necessidade de alternar repetidas vezes, os dois ambientes utilizados na realização das atividades diárias.

Todos os entrevistados, independentemente da modalidade de ensino, concordam que um sistema único, que possuísse tanto as funcionalidades inerentes ao sistema de gestão acadêmica, como o sistema de gestão da aprendizagem, além de facilitar sua prática, otimizaria seu tempo no cumprimento das atividades diárias.

Assim, a existência de pelo menos um ambiente intermediário, por meio do qual o docente possa acessar tanto o sistema de gestão acadêmica quanto o sistema de gestão da aprendizagem, é considerado, pelos docentes, um bom começo. Isso facilitaria a execução de algumas tarefas inerentes aos docentes e proporcionaria ao discente melhor qualidade no acesso às informações. Vale ressaltar também que um ambiente intermediário ou um sistema único precisa ser de fácil acesso e utilização, de forma a facilitar e a tornar ágil o desempenho da prática docente no que se refere às atividades administrativas e acadêmicas, como também pedagógicas e de comunicação.

Os docentes entrevistados demonstraram anseio por, no caso da integração entre os dois sistemas, de gestão acadêmica e de gestão da aprendizagem, esta ser imperceptível ao usuário. A Tabela 1 enumera os principais motivos para a integração entre os sistemas supracitados ou para a adoção de um sistema único que possua as funcionalidades pertinentes aos dois ambientes. 
Tabela 1: Principais motivos para a integração de ambos os sistemas

\begin{tabular}{c|l}
\hline 1 & $\begin{array}{l}\text { Otimização do tempo: no que concerne à realização das atividades administrativas, pedagógicas e } \\
\text { de comunicação, considerando que, para executar as suas atividades, o docente necessita alternar } \\
\text { entre os dois sistemas, o que é improdutivo. Isso pode confundir o docente, especialmente no caso } \\
\text { das funcionalidades presentes nos dois sistemas, o que pode levar o docente a executar a atividade } \\
\text { no ambiente errado. }\end{array}$ \\
\hline 2 & $\begin{array}{l}\text { Segurança da informação: é preciso que exista garantia e confiabilidade nos dados. O usuário } \\
\text { precisa sentir-se seguro quanto aos dados armazenados e às informações geradas pelo sistema. }\end{array}$ \\
\hline 3 & $\begin{array}{l}\text { Facilidade de uso: os usuários almejam trabalhar em sistemas fáceis de utilizar e intuitivos, pois as } \\
\text { dificuldades para aprender e explorar o "novo" são minimizadas, e os benefícios da ferramenta } \\
\text { tornam-se mais evidentes. A integração transparente ao usuário, na qual ele não perceba a existência } \\
\text { dos dois ambientes, sinaliza que a prática docente seria facilitada e simplificada. }\end{array}$ \\
\hline 4 & $\begin{array}{l}\text { Acompanhamento do desempenho do discente: a integração dos dados e informações presentes } \\
\text { nos dois sistemas podem produzir conhecimento para ajudar o docente a compreender o que } \\
\text { acontece no aprendizado do discente ou da turma. Esse conhecimento pode auxiliar o docente a } \\
\text { refletir sobre sua prática e, dessa forma, realizar os ajustes necessários de forma que o objetivo do } \\
\text { ensino seja alcançado. }\end{array}$ \\
\hline 5 & $\begin{array}{l}\text { Acesso a informações cadastrais e acadêmicas do discente: auxilia no processo de avaliação, pois } \\
\text { fornece argumentos para que o docente possa avaliar o discente, ponderando sobre seu desempenho } \\
\text { em semestres anteriores, ou em outras disciplinas. Essas informações possivelmente auxiliam ao } \\
\text { docente refletir e replanejar sua prática. }\end{array}$ \\
\hline
\end{tabular}

De forma geral, os docentes lecionam em várias turmas, atendem e acompanham muitos discentes, enfim, desempenham diversas atividades. Isso faz do tempo um aspecto precioso, como mencionado anteriormente. Portanto, a otimização do tempo foi um aspecto, entre tantos outros, muito valorizado pelos docentes entrevistados. Sendo assim, os sistemas de tecnologia utilizados devem estar voltados para o auxílio ao docente na sua atividade profissional, simplificado-a e otimizando-a.

A Tabela 2 relaciona algumas funcionalidades consideradas importantes - pelos entrevistados - à prática docente no que diz respeito aos dois sistemas. A necessidade de tais funcionalidades foi ratificada a partir do questionário de validação.

Tabela 2: Necessidades de funcionalidades identificadas em ambos os sistemas

\begin{tabular}{c|l}
\hline 1 & $\begin{array}{l}\text { Necessidades identificadas } \\
\text { funcionalidade objetiva garantir que as atividades enviadas pelo discente foram recebidas. }\end{array}$ \\
\hline 2 & $\begin{array}{l}\text { Existência de relatórios: relação dos discentes matriculados por turma, emissão de ata de presença, } \\
\text { ementa da disciplina, equivalência entre as disciplinas, perfil curricular do curso. }\end{array}$ \\
\hline 3 & $\begin{array}{l}\text { Funcionalidade para controle dos prazos definidos para a execução e entrega das atividades dos } \\
\text { discentes. }\end{array}$ \\
\hline 4 & $\begin{array}{l}\text { Funcionalidades que possibilitem o planejamento, registro e acompanhamento da disciplina, além do } \\
\text { controle das atividades planejadas e as realizadas, de modo a alertar o docente quanto ao não } \\
\text { cumprimento do planejamento. Possibilitar à coordenação e ao discente acompanhar o planejamento } \\
\text { da disciplina. }\end{array}$ \\
\hline 5 & $\begin{array}{l}\text { Importação/exportação de planejamentos a partir de documentos texto, planilhas e de unidades de } \\
\text { aprendizagem no padrão IMS LD }{ }^{10} \text {. }\end{array}$ \\
\hline 6 & $\begin{array}{l}\text { Funcionalidades de comunicação entre docente e discente, de forma que auxiliem o discente a } \\
\text { superar suas dificuldades e auxiliem o docente na reflexão da sua prática. }\end{array}$ \\
\hline 7 & $\begin{array}{l}\text { Funcionalidade de registro e acompanhamento do desempenho do discente: simplificar e viabilizar o } \\
\text { registro e acompanhamento do desempenho do discente e possibilitar ao discente o } \\
\text { acompanhamento de seu desempenho. }\end{array}$ \\
\hline 8 & \begin{tabular}{l} 
Relatórios que mostrem a evolução do processo de avaliação do discente e da turma, de forma a \\
\hline
\end{tabular}
\end{tabular}

\footnotetext{
${ }^{10}$ IMS LD é um padrão aberto - integrado a outras especificações, cujo objetivo é representar o processo de ensino-aprendizagem de uma maneira formal. Disponível em: $<$ http://www.imsglobal.org/learningdesign/ldv1p0/imsld_infovlp0.html>.
} 


\begin{tabular}{l|l}
\hline & $\begin{array}{l}\text { comparar o desempenho do discente em outras disciplinas, juntamente à verificação do desempenho } \\
\text { de turmas anteriores, de modo a criar estratégias para auxiliar a reflexão docente e o replanejamento } \\
\text { da disciplina. E relatórios que forneçam subsídios à equipe pedagógica para repensar novas } \\
\text { estratégias e responder questionamentos como: É prudente mudar de professor? O problema está na }\end{array}$ \\
$\begin{array}{l}\text { interação? O problema está no material? O problema é o embasamento? Isso no intuito de } \\
\text { possibilitar que seja aferido se o problema é pontual em determinada cidade, ou em determinada } \\
\text { disciplina. Que possibilite investigar o desempenho do discente na disciplina e orientá-lo na } \\
\text { condução de sua vida acadêmica, considerando os problemas de legislação. }\end{array}$ \\
\hline 9 & $\begin{array}{l}\text { Funcionalidades que possibilitem o acesso às informações acadêmicas, como notas, frequência, } \\
\text { calendário e plano de ensino. }\end{array}$ \\
\hline 10 & $\begin{array}{l}\text { Funcionalidades que possibilitem a realização de atividades on-line, e que possam ser corrigidas e } \\
\text { registradas automaticamente no sistema de gestão acadêmica. }\end{array}$ \\
\hline 11 & $\begin{array}{l}\text { O sistema de gestão da aprendizagem precisa considerar a estrutura de cursos de longa duração, por } \\
\text { exemplo, cursos universitários. }\end{array}$ \\
\hline
\end{tabular}

Considerando as necessidades dos usuários, os sistemas devem ser fáceis de utilizar e intuitivos. A integração entre os sistemas de gestão acadêmica e de gestão da aprendizagem precisa seguir sérios critérios e parâmetros de usabilidade. Esta é uma forma de minimizar as dificuldades em aprender e explorar o "novo", e tornar os benefícios da ferramenta mais evidentes.

Para os docentes entrevistados, a prática do processo de avaliação envolve o acompanhamento do desempenho do discente na disciplina, não apenas a quantificação do seu aprendizado. Portanto, o seu progresso é considerado e analisado de forma a possibilitar que o docente reflita sobre o processo de ensino-aprendizagem e sobre sua prática de ensino. Essa reflexão os faz ponderar, para que possam ser feitos os ajustes necessários nos seus planejamentos, de modo que o objetivo do ensino seja alcançado.

Integrando os dados e as informações existentes nos dois sistemas, pode ser gerado conhecimento para a reflexão do docente sobre o aprendizado do discente ou da turma. Desse modo, o acesso a informações cadastrais e acadêmicas do discente visa fornecer elementos importantes para a avaliação, considerando seu desempenho em semestres anteriores, ou em outras disciplinas.

No que concerne à integração entre os sistemas de gestão acadêmica e da aprendizagem para os docentes entrevistados, um ambiente que apenas possibilite alternar o acesso aos dois sistemas, evitando exclusivamente a execução de dois "logins"11 distintos, não é suficiente. O usuário deve ser capaz de prescindir a existência dos dois ambientes e poder acessar as informações acadêmicas e pedagógicas a partir de um único ponto. Isso facilitaria tanto a prática do docente como simplificaria o estudo para o discente.

Para que a implantação de novas tecnologias tenha sucesso, faz-se necessário acompanhar cuidadosamente os usuários visto que muitos dos entrevistados ratificaram que o não uso de algumas funcionalidades é resultante muito mais da falta de conhecimento técnico do que da falta de disposição em manusear novas tecnologias.

O panorama tecnológico atual, que se encontra em processo constante de inovação, sinaliza uma preocupação crescente em integrar os ambientes de gestão acadêmica e de gestão da aprendizagem. Tal integração visa, na esfera administrativa das instituições de ensino, facilitar o planejamento, o controle, a coordenação, a análise e o processo decisório.

No que diz respeito à esfera pedagógica objetiva otimizar a prática de planejamento, ensino e avaliação e, dessa forma, colaborar para que o docente faça uma justa e sensata reflexão de sua prática, de modo a realizar as adequações necessárias ao sucesso do processo de ensino-aprendizagem.

Múltiplos são os motivos que suscitam a necessidade do docente refletir sobre sua prática, a contar dos pequenos problemas que carecem ser resolvidos até o anseio de compreender o que está ocorrendo no processo de ensino-aprendizagem.

As entrevistas e os documentos analisados sugerem que a integração entre os sistemas de gestão acadêmica e da aprendizagem acarreta benefícios e auxilia o docente em sua prática, seja de planejamento, ensino, avaliação seja na reflexão desta. Cabe realçar que os docentes destacam a relevância da contribuição da autonomia conferida

\footnotetext{
${ }^{11}$ Acesso ao sistema.
} 
pelo sistema de gestão acadêmica ao discente no que tange à gerência de sua vida acadêmica. Do mesmo modo, enfatizaram a importância do sistema de gestão da aprendizagem no processo de ensino-aprendizagem.

Visando compreender e buscar soluções para as necessidades e os problemas vivenciados pelas instituições pesquisadas, observaram-se indícios de que, por meio da integração das informações - geradas pelo sistema de gestão acadêmica e gestão da aprendizagem - é possível averiguar o que está acontecendo no processo de ensinoaprendizagem. Isso acarreta a reflexão da prática docente na gestão do curso, bem como a reflexão dos responsáveis pela gestão da educação.

\section{Requisitos e protótipos sugeridos}

Os dados coletados nesta pesquisa foram tratados e categorizados com auxílio do software NVivo $8^{12}$. Destarte, o uso dessa ferramenta ajudou a estabelecer os requisitos relacionados na Tabela 3.

As Tabelas 3, 4 e 5 estão organizadas considerando, inicialmente, a prática docente de planejamento, ensino e avaliação, respectivamente. Todas as tabelas estão seguidas pela identificação do requisito e sua respectiva descrição, que foram estabelecidos segundo as necessidades identificadas.

Tabela 3: Requisitos estabelecidos - prática do planejamento

\begin{tabular}{c|c|l}
\hline Prática & Requisito & \multicolumn{1}{c}{ Descrição } \\
\hline \multirow{5}{*}{ Planejamento } & [REQ_01] & $\begin{array}{l}\text { Registro do planejamento: a funcionalidade deve considerar o } \\
\text { calendário acadêmico e administrativo da instituição e a ementa do } \\
\text { curso. O docente teria de informar: as atividades planejadas para a } \\
\text { data, os recurso/serviços necessários à execução da atividade, o } \\
\text { responsável pela execução da atividade. }\end{array}$ \\
\cline { 2 - 4 } & [REQ_02] & $\begin{array}{l}\text { Reutilização de planejamento: a funcionalidade deve permitir } \\
\text { reutilizar planejamentos anteriores. }\end{array}$ \\
\cline { 2 - 4 } & [REQ_03] & $\begin{array}{l}\text { Importação/exportação de planejamentos: a funcionalidade deve } \\
\text { permitir a importação/exportação de planejamento, a partir de } \\
\text { documentos textos, planilhas e de unidades de aprendizagem no } \\
\text { padrão IMS LD. }\end{array}$ \\
\cline { 2 - 4 } & [REQ_04] & $\begin{array}{l}\text { Visualização do planejamento: a funcionalidade deve possibilitar } \\
\text { ao discente e à coordenação visualizar o planejamento. Tal } \\
\text { visualização deve deixar claro o que foi planejado e o que foi } \\
\text { executado. }\end{array}$ \\
\cline { 2 - 4 } & [REQ_05] & $\begin{array}{l}\text { Controle e acompanhamento do planejamento pelo docente: o } \\
\text { sistema deve possuir uma funcionalidade que controle as } \\
\text { atividades planejadas e executadas, de forma a alertar o docente } \\
\text { quanto ao cumprimento do seu planejamento. }\end{array}$ \\
\cline { 2 - 4 } & [REQ_06] & $\begin{array}{l}\text { Identificação de discentes repetentes na turma: a funcionalidade } \\
\text { deve indicar ao docente quais discentes são repetentes. }\end{array}$ \\
\hline
\end{tabular}

Tabela 4: Prática do ensino

\begin{tabular}{c|c|l}
\hline Prática & Requisito & \multicolumn{1}{c}{ Descrição } \\
\hline \multirow{4}{*}{ Ensino } & [REQ_01] & $\begin{array}{l}\text { Chat com vídeo: o sistema deve disponibilizar a funcionalidade } \\
\text { "chat com vídeo". }\end{array}$ \\
\cline { 2 - 4 } & [REQ_02] & $\begin{array}{l}\text { Perguntas e respostas gravadas em áudio ou vídeo: a } \\
\text { funcionalidade deve possibilitar o envio de perguntas e respostas } \\
\text { gravadas em áudio ou vídeo. }\end{array}$ \\
\cline { 2 - 4 } & [REQ_03] & $\begin{array}{l}\text { Whiteboard: o sistema deve disponibilizar uma funcionalidade de } \\
\text { chat, que possibilite trabalho colaborativo, ou seja, o docente } \\
\text { explicando em uma tela e o discente assistindo, podendo interferir } \\
\text { naquela mesma tela em que o docente está escrevendo. }\end{array}$ \\
\cline { 2 - 4 } & [REQ_04] & Escrita científica: funcionalidade que possibilite a escrita \\
\hline
\end{tabular}

\footnotetext{
${ }^{12}$ Nivo8 - QSR International. Disponível em: <http://www.qsrinternational.com/products_nvivo.aspx>.
} 


\begin{tabular}{l|l|l}
\hline & & científica, como: a linguagem matemática e estruturas químicas. \\
\cline { 2 - 3 } & [REQ_05] & $\begin{array}{l}\text { Habilitar/ocultar material: funcionalidade que possibilite } \\
\text { habilitar/ocultar, por turma, material já disponibilizado no } \\
\text { ambiente. }\end{array}$ \\
\hline
\end{tabular}

Tabela 5: Prática da avaliação

\begin{tabular}{|c|c|c|}
\hline Prática & Requisito & Descrição \\
\hline \multirow{13}{*}{ Avaliação } & [REQ_01] & $\begin{array}{l}\text { Estudo dirigido: funcionalidade que possibilite o estudo dirigido. O } \\
\text { discente vai respondendo a atividade e o próprio sistema, no caso } \\
\text { de respostas erradas, corrige, explica e justifica a resposta. }\end{array}$ \\
\hline & [REQ_02] & $\begin{array}{l}\text { Avaliações on-line: funcionalidade que possibilite a realização de } \\
\text { atividades ou avaliações on-line, e que corrija, e pontue o } \\
\text { desempenho do discente na avaliação realizada. }\end{array}$ \\
\hline & [REQ_03] & $\begin{array}{l}\text { Acesso aos dados do discente: funcionalidade que permite ao } \\
\text { docente o acesso aos dados cadastrais e acadêmicos de seus } \\
\text { discentes. }\end{array}$ \\
\hline & [REQ_04] & $\begin{array}{l}\text { Informações sobre o desempenho: funcionalidade que informe ao } \\
\text { discente o seu desempenho em atividades ou avaliações. }\end{array}$ \\
\hline & [REQ_05] & $\begin{array}{l}\text { Registro e acompanhamento do desempenho do discente: o sistema } \\
\text { deve disponibilizar uma planilha para que o docente registre a } \\
\text { frequência, as notas, conceitos e observações dos discentes nas } \\
\text { atividades desenvolvidas ao longo da disciplina, } \\
\text { independentemente da fórmula de avaliação adotada na instituição. } \\
\text { Nessa planilha deve estar bem definido o registro da avaliação por } \\
\text { aula, bem como o registro das avaliações somativas. }\end{array}$ \\
\hline & [REQ_06] & $\begin{array}{l}\text { Fórmula de avaliação: o sistema deve disponibilizar uma } \\
\text { funcionalidade que possibilite ao docente criar sua própria fórmula } \\
\text { de avaliação para, posteriormente, ser convertida para a fórmula de } \\
\text { avaliação adotada pela instituição. }\end{array}$ \\
\hline & [REQ_07] & $\begin{array}{l}\text { Ambiente para divulgação de notas e faltas: a funcionalidade deve } \\
\text { disponibilizar o total de faltas e as notas definidas. A } \\
\text { disponibilização deve ser individual para o discente. Para o docente } \\
\text { ou para a coordenação deve ser feita considerando um discente em } \\
\text { particular, ou a turma. }\end{array}$ \\
\hline & [REQ_08] & $\begin{array}{l}\text { Comparação de desempenho entre turmas: a funcionalidade deve } \\
\text { possibilitar a comparação do desempenho da turma atual em face } \\
\text { das turmas anteriores. }\end{array}$ \\
\hline & [REQ_09] & $\begin{array}{l}\text { Acesso ao mapa de notas do docente: a funcionalidade deve } \\
\text { permitir à coordenação o acesso ao mapa de notas, constituído pela } \\
\text { fórmula de avaliação criada pelo docente, que inclui todos os } \\
\text { elementos considerados para compor } \mathrm{a}(\mathrm{s}) \text { nota(s). }\end{array}$ \\
\hline & [REQ_10] & $\begin{array}{l}\text { Relatórios qualitativos: que evidenciem o desempenho da turma } \\
\text { como um todo, bem como do discente individualmente. }\end{array}$ \\
\hline & [REQ_11] & $\begin{array}{l}\text { Ata eletrônica: esse sistema deve dispor de ata eletrônica, no caso } \\
\text { de atividades enviadas por e-mail ou postadas no fórum. Esta } \\
\text { funcionalidade visa garantir o recebimento das atividades enviadas } \\
\text { pelo discente. }\end{array}$ \\
\hline & [REQ_12] & $\begin{array}{l}\text { Relatórios: relação dos discentes matriculados por turma, emissão } \\
\text { de ata de presença, ementa da disciplina, equivalência entre as } \\
\text { disciplina, perfil curricular do curso. }\end{array}$ \\
\hline & [REQ_13] & $\begin{array}{l}\text { Controle de prazos: funcionalidade que possibilite o controle dos } \\
\text { prazos definidos para a execução e entrega das atividades. }\end{array}$ \\
\hline
\end{tabular}

O protótipo do design de um produto permite aos usuários interagir com ele e explorar a sua conformidade, testar, enfim, refletir sobre o design proposto. Nesse trabalho, foi utilizada a técnica de prototipagem de baixa 
fidelidade, tendo sido utilizando o software Balsamiq ${ }^{13}$, que é indicado para a criação de protótipos, entre outras aplicações. As Figuras 1, 2 e 3 representam alguns dos protótipos sugeridos, e que foram avaliados pelos participantes.
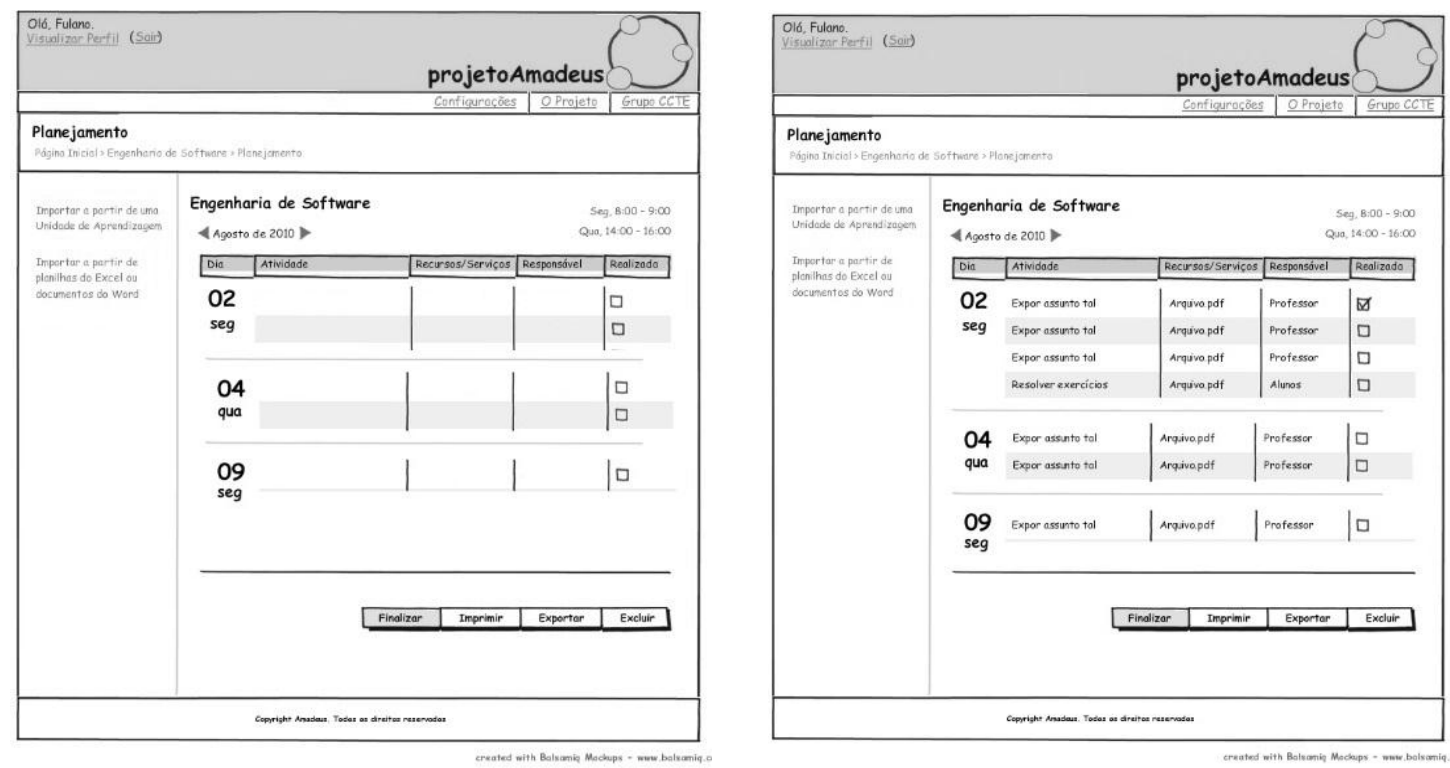

Figura 1: Protótipos para a prática de planejamento: registro do novo planejamento
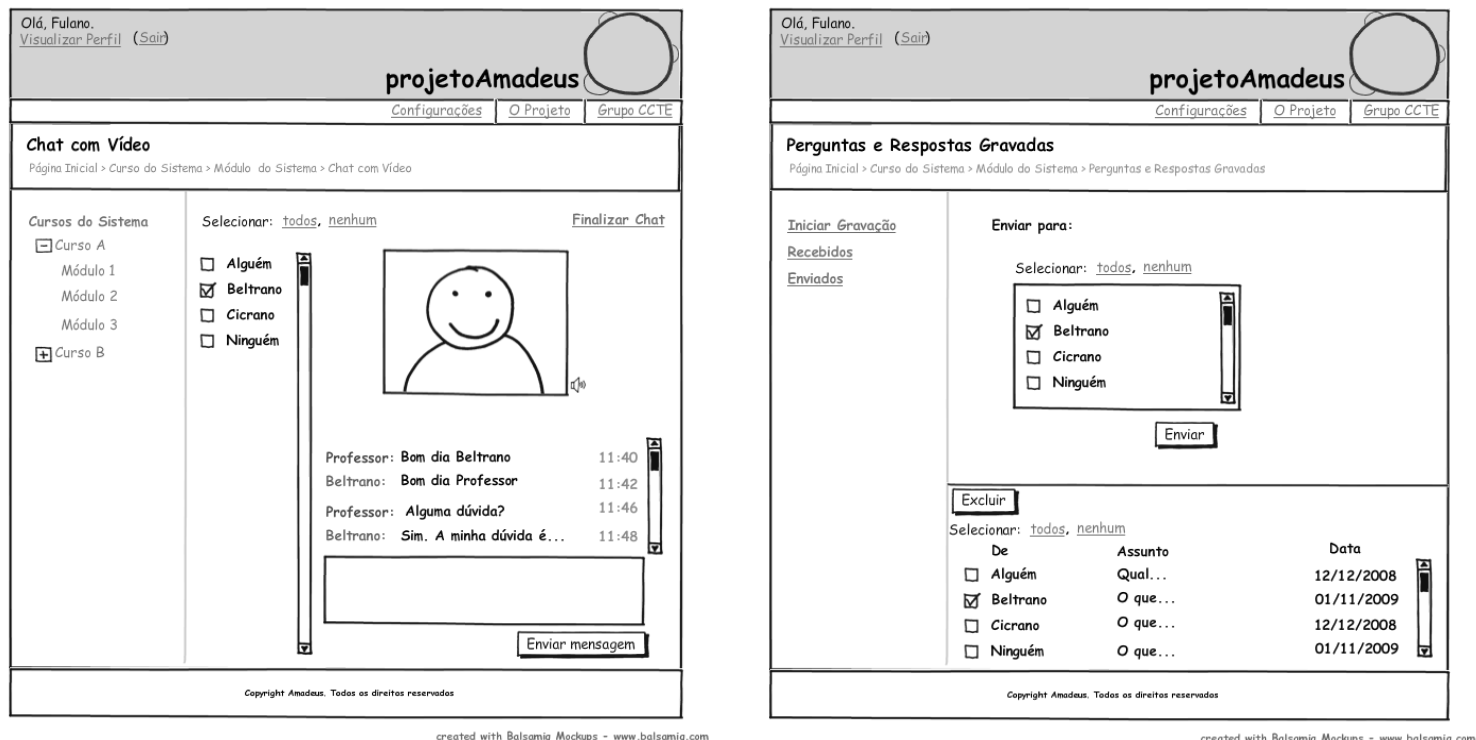

Figura 2: Protótipos para a prática de ensino: chat com vídeo e perguntas e respostas gravadas

\footnotetext{
${ }^{13}$ Disponível em: <http://www.balsamiq.com/products/mockups/desktop>.
} 


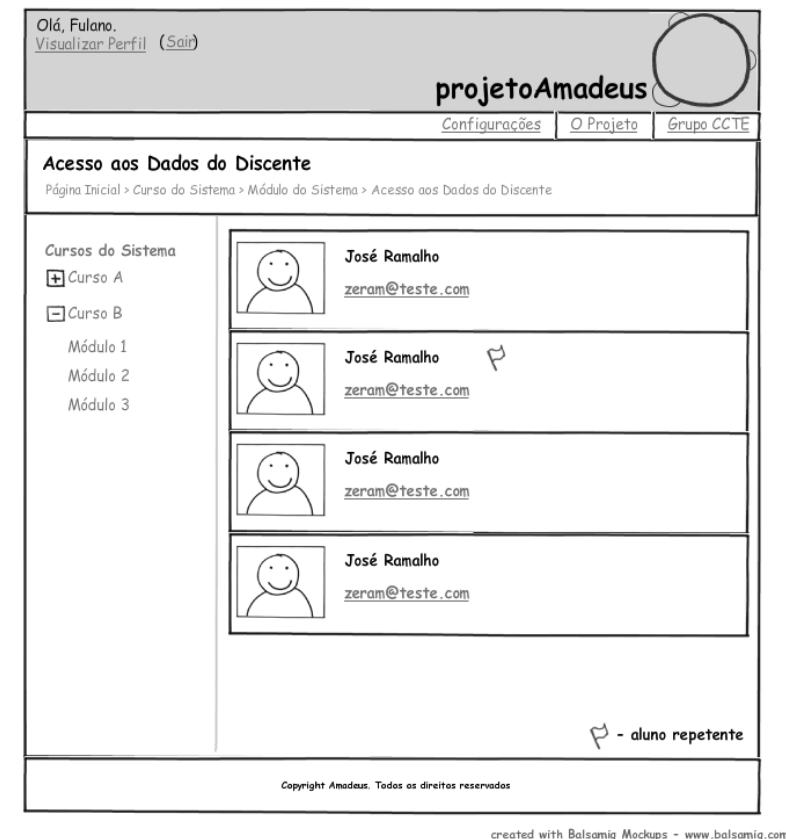

Figura 3: Protótipo para a prática de avaliação: acesso aos dados do discente

\section{Considerações finais}

Os resultados desta pesquisa sugerem que um sistema único simplificaria e facilitaria a atividade dos docentes e o acesso do discente às informações do seu perfil. Dessa forma, o tempo empregado no cumprimento das atividades administrativas e pedagógicas seria otimizado. Também facilitaria o acesso às informações do discente, vistas como necessárias ao processo de avaliação por aqueles docentes que consideram todos os aspectos envolvidos na evolução do desempenho do discente na ocasião de avaliá-lo. Entretanto, modificar uma prática não é um processo que ocorra abruptamente. É preciso orientar e apontar os benefícios que podem ser produzidos no processo de ensino-aprendizagem pelo uso de tais tecnologias.

Nesse sentido, o posicionamento da instituição quanto à utilização, pelos docentes, de um sistema de gestão acadêmica, bem como de um sistema gestão de aprendizagem, é fator decisivo. A instituição necessita explicar o uso operacional, bem como esclarecer ao docente quanto ao potencial pedagógico do uso desses sistemas em sua prática.

Este trabalho, a partir de uma abordagem centrada no usuário, focou a prática docente visando simplificá-la, otimizá-la, e contribuir para com a reflexão do docente sobre o processo de ensino-aprendizagem. Produziu resultados que podem sugerir novas pesquisas, dentre as quais:

- verificar se as informações administrativas e pedagógicas inerentes ao processo de ensino-aprendizagem, quando integradas, possibilitam conhecer como está ocorrendo o processo de ensino-aprendizagem, bem como se essa integração contribui para a reflexão da prática docente na gestão do curso e na gestão dos responsáveis pela educação;

- verificar se a adoção de um único "sistema de gestão pedagógica" - que englobe tanto as funcionalidades administrativas inerentes aos sistemas de gestão acadêmica, bem como as funcionalidades pedagógicas e de comunicação inerentes aos sistemas de gestão da aprendizagem - realmente contribuem na reflexão da prática docente e, consequentemente, no processo de ensino-aprendizagem.

Os resultados desta pesquisa foram prototipados e reportados à comunidade do LMS Amadeus no PSBB Portal do Software Público Brasileiro do Ministério do Planejamento da República Federativa do Brasil. É importante lembrar que as contribuições geradas por esta pesquisa podem ser aplicadas a outros LMS, visto que o processo de avaliação deve ser contínuo, de forma que as necessidades identificadas possam ser incorporadas. E, a partir destas, novas avaliações possam ser realizadas, com vistas ao aprimoramento da prática docente. 


\section{Referências}

[1] FONSECA, H. R. M. Análise da evolução da educação. Disponível em: $<$ http://www.webartigos.com/articles/13461/1/analise-da-evolucao-da-educacao/pagina1.html>. Acesso em: 28 jul. 2009.

[2] PERRENOUD. P. A. Prática reflexiva no ofício de professor: profissionalização e razão pedagógica. Porto Alegre-RS: Artmed, 2002. p. 13.

[3] TARDIFF, M. Saberes docentes e formação profissional. Petrópolis-RJ: Vozes, 2007.

[4] SANTOS, A. L; LUIS, J.; SILVA, P. G. Formação e práticas pedagógicas - múltiplos olhares no ensino das ciências. Artigo: A influência das tecnologias da informação e da comunicação (TIC) no ensino das ciências. Recife-PE: Bargaço, 2008.

[5] CORTIMIGLIA, M. N. Qualificando - ambiente virtual de aprendizagem via internet. Disponível em: $<$ http://www.lume.ufrgs.br/bitstream/handle/10183/6497/000485955.pdf?sequence=1>. Acesso em: 19 jan. 2009.

[6] LÜDKE, M; ANDRÉ, M. E. D. Pesquisa em educação: abordagens qualitativas. São Paulo - SP: E.P.U, 1986. p. 9.

[7] PREECE, J.; ROGERS,Y.; SHARP, H. Design da interação - além da interação homem-computador. Porto Alegre-RS: Bookman, 2005. p. 420.

[8] LOPES, E. M. M. EAD: mudança de paradigmas pedagógicos. Disponível em: $<$ http://www.administradores.com.br/artigos/ead_mudanca_de_paradigmas_pedagogicos/23386/>. Acesso em: 5 nov. 2008. 